\title{
Echocardiographic evaluation of right and left heart findings according to the severity of the disease in stable chronic obstructive pulmonary disease.
}

\author{
Pinar Mutlu*, Ercan Aksit, Arzu Mirici N \\ Clinic of Chest Diseases, Can State Hospital, Canakkale, Turkey
}

\begin{abstract}
Introduction: Chronic Obstructive Pulmonary Disease (COPD) is seen alongside some systemic diseases that result in impaired functional capacity, worsening dyspnea, decreased health-related quality of life and increased mortality. Cardiovascular diseases, considering their effect on mortality, play an important role in such diseases.

Objective: The aim of this study to evaluate the cardiac changes that develop secondary to COPD and attempt to identify any correlation between the severities of the disease determined using GOLD guidelines and ECHO findings.

Method: This prospective study involved 32 male patients who presented to the pulmonary disease outpatient clinic with stable COPD. We compared the severity of COPD with the ECO findings of the patients.

Findings: Correlations were found between the severity of COPD and heart rate, the number of cigarettes smoked and the respiratory function test results. Measurable tricuspid regurgitation was detected in 26 patients $(26 / 32=81.2 \%)$, and the degree of tricuspid regurgitation according to the severity of COPD.

Conclusion: We suggest that cardiac influences should be diagnosed early in the course of the disease, and that treatment be started to decrease the rates of mortality and morbidity in patients with COPD.
\end{abstract}

Keywords: Echocardiography, Chronic obstructive pulmonary disease, Right ventricle outflow, Ejection fraction.

Accepted on April 27, 2018

\section{Introduction}

Chronic Obstructive Pulmonary Disease (COPD) has been defined as a disease that develops as a result of the abnormal inflammatory response of the lungs to the harmful particles or gasses, although the effects of systemic inflammation may also be seen [1]. COPD is a significant cause of mortality and morbidity with increasing incidence around the world. COPD was the $5^{\text {th }}$ leading cause of death in 2002, according to the World Health Organization (WHO), and is estimated to become the 4th leading cause of death by 2030 [2]. COPD is also seen alongside some systemic diseases that result in impaired functional capacity, worsening dyspnea, decreased health-related quality of life and increased mortality. Cardiovascular diseases, considering their effect on mortality, play an important role in such diseases.

The association between COPD and the development of cardiovascular disease can be evaluated in two groups. First, related to the presence of common risk factors, such as cigarette smoking, advanced age and gender, and second, related to ventricular dysfunction due to increased intrathoracic pressure and the deterioration of cardiac function due to primary lung disease, such as pulmonary hypertension.
Echocardiography (ECHO) is a quick, non-invasive and a relatively accurate means of evaluation right ventricle function, left ventricular filling pressure, tricuspid failure, left ventricle function and valve function. In the present study, we use ECHO to evaluate the cardiac changes that develop secondary to COPD and attempt to identify any correlation between the severities of the disease determined using GOLD guidelines and ECHO findings.

\section{Patients and Methods}

This prospective study involved 32 male patients who presented to the pulmonary disease outpatient clinic with stable COPD between February 2017 and November 2017. Informed consent was obtained from all patients, and this study was approved by the local ethics committee.

The diagnosis of COPD was based on a history of 10 packs/ year cigarette smoking, symptoms suggestive of COPD, physical examination findings, radiographic findings and spirometric measurements. Spirometry was performed on all patients in line with the American Respiratory SocietyEuropean Respiratory Society guidelines and using a Masterscope JLAB V5.22.1.50 (Cardinal Health, Germany, Hoechberrg, 2006) spirometry system. Forced expiratory 
volume was obtained in the first second (FEV1), and Forced Vital Capacity (FVC), FEV1/FVC ratio and mean forced expiratory flow at $25-75 \%$ (FEF\% 25-75) were obtained. All spirometric tests were conducted by a technician who was blind to the echocardiographic findings. The patients were divided into four groups in line with the guidelines of Global Initiative for Chronic Obstructive Lung Disease (GOLD) as mild (FEV1 $\geq 80 \%$ expected value), intermediate $(50 \% \leq$ FEV $1<80 \%$ expected value), severe $(30 \% \leq$ FEV $1<30 \%$ expected value) and very severe $(30 \% \leq \mathrm{FEV} 1<50 \%$ expected value), provided that the expected post-bronchodilator FEV1/FVC ratio was less than $70 \%$ [3].

Patients with tachycardia, arrhythmia, valvular cardiac disease, coronary artery disease and any systemic or cardiac diseases that may cause pulmonary hypertension (e.g. tricuspid valve disorder, left ventricular dysfunction), any malignant tumors, head and neck abnormalities, patients with exacerbations in the last four weeks, patients with a weak echo window and patients who could not perform spirometry were excluded from this study.

A two-dimensional transthoracic Doppler echocardiography was performed on all patients while in the left lateral lying position using a Vivid 7 device (GE Vingmed, US) and a 2.5 $\mathrm{MHz}$ transducer, with the same cardiologist making all measurements who was blind to the respiratory function test findings of the patients. All measurements were performed during at least three consecutive cardiac cycles and normal respiration and at the end of expirium.

Right atrial volume was measured using the Modified Simpson's technique in an apical window and four-chamber view. The S, E and A of the free wall of the right ventricle was measured, and the E/A ratio was calculated.

Pulmonary Artery Systolic Pressure (SPAP) was determined through a continuous wave Doppler evaluation of tricuspid insufficiency [4,5], while peak flow was measured from the pulmonary valve flow record, and Pulmonary Acceleration Time (PAT) was measured as the time between the initiation and the peak of the flow. Tricuspid Annular Plane Systolic Excursion (TAPSE) and RV longer axe function were recorded from a four-apical chamber view obtained by an M-mode probe placed on the free wall angle of the tricuspid valve. The distance between the tricuspid ring and RV apex was measured at the end of the diastole and systole of the same cardiac cycle, and TAPSE was calculated as the difference between the enddiastolic and end-systolic measurements (in $\mathrm{mm}$ ) [6].
For the calculation of the values of the dimension of the Right Ventricle Outflow Tract (RVOT) and RVOT Fractional Shortening (RVOT-FS), two-dimensional echocardiograms of the parasternal short axis view at the aortic root level were used. End-diastolic (at the start of the Q wave) and end systolic (at the end of the T wave) diameters were measured using the M-mode records of RVOT. RVOT-FS was calculated as the percentage decrease in the diastolic RVOT diameter using the same M-mode images reported by Lindqvist et al. [7]. Furthermore, the tricuspid S-wave was calculated using tissue Doppler images of the lateral wall of the tricuspid valve as an indicator of the systolic function of the right ventricle.

E waves were calculated as a marker of RV diastolic functions, A waves and deceleration times were calculated using the tricuspid inflow pulse waves, and E' waves were calculated from the A' waves and the tissue Doppler images obtained at the level of the lateral annulus [8]. Left ventricular systolic function was evaluated by measuring the ejection fraction using the Teichholz method. EF (Ejection Fraction) was calculated as the measurement of the end diastolic value leaving the LV (56-78\%) during each contraction.

\section{Statistical analysis}

The data were analysed using the SPSS Package Program Version 20.0 (IBM Corporation, Armonk, New York, US). Descriptive data were presented in numbers, percentages, standard deviation, median, minimum and maximum values. A Chi-Square Test was used in the analysis of categorical variables, while continuous variables were compared using a Kruskal Wallis Test. $\mathrm{P}<0.05$ was accepted as statistically significant.

\section{Findings}

A total of 32 patients (all male, with a mean age of $64.6 \pm 9.7$ y) with COPD who complied with the inclusion criteria were included in this study. The demographics of the patients and the severity of COPD are presented in Table 1.

Correlations were found between the severity of COPD and heart rate, the number of cigarettes smoked and the respiratory function test results. Measurable tricuspid regurgitation was detected in 26 patients $(26 / 32=81.2 \%)$, and the degree of tricuspid regurgitation according to the severity of COPD was demonstrated in Table 2.

Table 1. Distribution of demographics by severity of COPD.

\begin{tabular}{|c|c|c|c|c|c|}
\hline Severity of COPD & Mild $(n=4)$ & Intermediate $(n=14)$ & Severe $(n=10)$ & Very severe $(n=4)$ & p-value \\
\hline Age $(y)$ & $65.0 \pm 9.8$ & $63.1 \pm 10.5$ & $61.8 \pm 5.9$ & $60.5 \pm 11.3$ & 0.4 \\
\hline $\mathrm{BMI}\left(\mathrm{kg} / \mathrm{m}^{2}\right)$ & $29.5 \pm 6.4$ & $28.2 \pm 6.9$ & $27.7 \pm 5.6$ & $25.3 \pm 7.8$ & 0.5 \\
\hline Heart rate (bpm) & $75.5 \pm 7.7$ & $76.8 \pm 3.8$ & $81.5 \pm 4.2$ & $86.3 \pm 7.2$ & 0.001 \\
\hline Cigarette Smoking (packs/y) & $36.5 \pm 17.3$ & $41.9 \pm 16.1$ & $32.5 \pm 16.5$ & $61.3 \pm 59.5$ & $\leq 0.05$ \\
\hline
\end{tabular}


Echocardiographic evaluation of right and left heart findings according to the severity of the disease in stable chronic obstructive pulmonary disease

\begin{tabular}{|c|c|c|c|c|c|}
\hline FVC & $3590 \pm 577.2$ & $2785.7 \pm 579.4$ & $2531.3 \pm 251.3$ & $1887.5 \pm 466.7$ & $\leq 0.05$ \\
\hline FVC percentage & $98.2 \pm 11.8$ & $83.9 \pm 10.9$ & $64.9 \pm 10.2$ & $50.8 \pm 12.6$ & $\leq 0.05$ \\
\hline FEV1 & $2522.5 \pm 474.3$ & $1722.9 \pm 391.4$ & $1286.0 \pm 221.8$ & $752.5 \pm 105.6$ & $\leq 0.05$ \\
\hline FEV1 percentage & $88.8 \pm 14.5$ & $65.4 \pm 8.4$ & $42.1 \pm 5.2$ & $25.7 \pm 3.3$ & $\leq 0.05$ \\
\hline FEV1/FVC & $68.9 \pm 1.1$ & $61.0 \pm 8.2$ & $52.2 \pm 10.5$ & $40.6 \pm 6.1$ & $\leq 0.05$ \\
\hline
\end{tabular}

SD: Standard Deviation, BMI: Body Mass Index; FEV1: Forced Expiratory Volume in the first second; FVC: Forced Vital Capacity.

Table 2. Degree of tricuspid regurgitation by severity of COPD.

\begin{tabular}{llllll}
\hline Severity of COPD & Mild $(\mathbf{n}=\mathbf{4})$ & Intermediate $(\mathbf{n}=\mathbf{1 4})$ & Severe $(\mathbf{n}=\mathbf{1 0})$ & Very severe $(\mathbf{n}=\mathbf{4})$ & $\mathbf{p}$-value \\
\hline Tricuspid insufficiency & $\mathrm{n}(\%)$ & $\mathrm{n}(\%)$ & $\mathrm{n}(\%)$ & $\mathrm{n}(\%)$ & $0.622^{*}$ \\
\hline Trace no regurgitation & $1(16.7)$ & $2(33.3)$ & $3(50.0)$ & $0(0.0)$ & $3(14.3)$ \\
\hline Mild insufficiency & $3(14.3)$ & $9(42.9)$ & $6(28.6)$ & $1(20.0)$ & $1(20.0)$ \\
\hline Intermediate insufficiency & $0(0.0)$ & $3(60.0)$ & & & \\
\hline $\mathrm{p}^{*}:$ Chi-Square test & & & &
\end{tabular}

Pulmonary Hypertension (PH) is defined as resting SPAB $\geq 30$ $\mathrm{mmHg}$ [9]. $\mathrm{PH}$ is divided into categories, such as mild, intermediate and severe, based on SPAP values of 30-50 $\mathrm{mmHg}, 50-70 \mathrm{mmHg}$, and $>70 \mathrm{mmHg}$, respectively. $\mathrm{PH}$ was detected in five patients in the present study $(5 / 32=15.6 \%)$, and all of these patients were in the severe and very severe COPD groups and had a mild $\mathrm{PH}$.

The right ventricle dimension was measured using an M-mode echo, and a diagnosis of cor pulmonale was made when the width of the right ventricle exceeded $2.6 \mathrm{~cm}$. Cor pulmonale was diagnosed in two patients with very severe COPD in the present study, while left heart failure was detected in one patient with intermediate COPD.

No significant difference was found in the ECHO findings related to the severity of COPD.

\section{Discussion}

Although COPD is associated with changes in the structure and function of the right heart $[10,11]$, functional disorder of the left heart has also been demonstrated independent of the stage of the disease in COPD. A common ECHO finding in patients with COPD is left ventricular diastolic dysfunction, although symptoms of heart failure may not be present. An association between decreased physical activity and left ventricular dysfunction has been demonstrated, independent of the stage of COPD, which is defined according to the spirometric GOLD staging criteria in patients with COPD [12]. The present study aimed to evaluate the functions of both the right and left heart using ECHO findings (Table 3).

Table 3. Comparison of ECHO findings by severity of COPD.

\begin{tabular}{|c|c|c|c|c|c|}
\hline Severity of COPD & Mild (n=4) & Intermediate $(n=14)$ & Severe $(n=10)$ & Very severe $(n=4)$ & p value \\
\hline RVOT end-diastolic diameter & $32.5 \pm 3.4$ & $29.9 \pm 4.1$ & $29.5 \pm 5.7$ & $28.8 \pm 6.8$ & 0.637 \\
\hline RVOT end-systolic diameter & $18.0 \pm 5.4$ & $16.1 \pm 2.4$ & $15.2 \pm 3.3$ & $16.5 \pm 2.4$ & 0.838 \\
\hline RVOT-FS & $47.3 \pm 7.4$ & $44.3 \pm 7.3$ & $39.9 \pm 7.3$ & $40.8 \pm 11.2$ & 0.243 \\
\hline TAPSE & $19.5 \pm 1.7$ & $19.4 \pm 4.0$ & $21.5 \pm 5.9$ & $19.3 \pm 5.4$ & 0.944 \\
\hline SPAB & $20.3 \pm 6.1$ & $21.1 \pm 6.8$ & $22.2 \pm 8.8$ & $28.0 \pm 6.8$ & 0.345 \\
\hline PAT & $103.0 \pm 18.0$ & $129.5 \pm 30.7$ & $124.4 \pm 44.9$ & $121.3 \pm 36.9$ & 0.312 \\
\hline LVEDD & $44.8 \pm 5.2$ & $47.3 \pm 5.4$ & $47.0 \pm 5.1$ & $47.8 \pm 5.9$ & 0.861 \\
\hline LVESD & $29.8 \pm 3.2$ & $32.1 \pm 4.2$ & $31.7 \pm 4.3$ & $32.3 \pm 5.3$ & 0.836 \\
\hline LVEF & $62.0 \pm 1.2$ & $60.4 \pm 4.8$ & $61.3 \pm 4.3$ & $60.5 \pm 4.4$ & 0.801 \\
\hline Intraventricular septum & $11.8 \pm 0.9$ & $12.1 \pm 1.3$ & $12.0 \pm 1.3$ & $11.0 \pm 1.2$ & 0.578 \\
\hline
\end{tabular}




\begin{tabular}{|c|c|c|c|c|c|}
\hline RA diameter & $39.3 \pm 4.6$ & $40.1 \pm 3.5$ & $39.3 \pm 5.4$ & $38.5 \pm 2.1$ & 0.613 \\
\hline RV diameter & $35.5 \pm 7.6$ & $37.6 \pm 2.4$ & $37.1 \pm 5.3$ & $38.3 \pm 2.5$ & 0.887 \\
\hline LA diameter & $38.8 \pm 2.2$ & $41.2 \pm 4.6$ & $39.1 \pm 6.4$ & $36.5 \pm 2.5$ & 0.279 \\
\hline E/A ratio & $0.6 \pm 0.2$ & $0.5 \pm 0.2$ & $0.7 \pm 0.1$ & $0.5 \pm 0.2$ & 0.066 \\
\hline E'/A' ratio & $0.7 \pm 0.1$ & $0.5 \pm 0.2$ & $0.7 \pm 1.5$ & $0.6 \pm 0.1$ & 0.052 \\
\hline Tricuspid S-wave & $0.75 \pm 0.50$ & $0.64 \pm 0.49$ & $0.50 \pm 0.53$ & $0.75 \pm 0.50$ & 0.758 \\
\hline
\end{tabular}

SD: Standard Deviation; \%: Percentage of line; p: Kruskal Wallis Test; RVOT: Right Ventricle Outflow Tract; RVOT-FS: Right Ventricle Outflow Tract Fractional Shortening; TAPSE: Tricuspid Annular Systolic Excursion; SPAP: Systolic Pulmonary Artery Pressure; PAT: Pulmonary Acceleration Time; LVEDD: Left Ventricle EndDiastolic Diameter; LVESD: Left Ventricle End Systolic Diameter; LVEF: Left Ventricle Ejection Fraction; RA Right Atrium; RV: Right Ventricle; LA: Left Atrium.

Although ECHO is a non-invasive diagnostic test, it may be technically limited in a substantial percentage of patients with COPD. The configuration of the chest wall, air imprisonment and changes in the structure of the heart ventricles complicate ultrasonographic evaluations of the heart in patients with COPD [13,14]. In this study, 32 patients with COPD at different stages of the disease, and in whom an echocardiographic evaluation could be performed, were included.

Although the actual prevalence of $\mathrm{PH}$ is unknown, increased SPAP has been reported at $5-40 \%$ in series of selected individuals with serious COPD and with the previous right heart catheterization. However, in the large majority of cases, COPD-related $\mathrm{PH}$ is mild to intermediate and progress is slow without changing RV function; and severe $\mathrm{PH}$ is seen in less than $5 \%$ of the patients $[15,16]$. PH was identified in $15.6 \%$ of cases in the present study, and all of those patients were in the severe and very severe COPD groups, and their PH was mild.

Currently, routine evaluations of the presence of $\mathrm{PH}$ is not part of the COPD guidelines, although right ventricle dysfunction and $\mathrm{PH}$ is well known to impair the clinical course of COPD and to be directly proportionate with mortality [17]. New parameters are required to determine structural RV changes early in their course in COPD, with most of the recommended methods for the evaluation of RV function being based on volumetric measurements of the right ventricle. These approaches can be considered limited, firstly, for being dependent on the volume-related measurements, such as ejection fraction, and secondly, due to the complicated geometry of the right ventricle. This can be overcome using parameters that are independent of geometry, such as TAPSE [18].

As for the value of the RVOT function, Lindqvist [7] and Asmer [19] reported that RVOT movement or contraction could be used as a marker of RV systolic function in two different studies. Lindqvist et al. reported that RVOT-FS was intermediately correlated with TAPSE and inversely correlated with a transtricuspid Doppler gradient [7]. In a study by Geyik et al. [20], contrasting the present study, the RVOT dimension and contraction were found to be correlated with functional capacity and the degree of COPD, although TAPSE and PH values were not impaired in the COPD and control groups.
Studies that demonstrated a correlation between the stage of COPD and E/A ratio have been published in the literature $[21,22]$, although there have also been reports identifying no correlation between the parameters of right ventricular diastolic function and SFT parameters in cases with COPD [23]. In a study by Yemenici et al. [24], a significant positive correlation was identified between the E/A ratio and FEV1, and IVRT was found to be significantly lengthened in patients with an FEV $1<1 \mathrm{~L}$ when compared to patients with an FEV1 $>1$ L in COPD. In this regard, impairments in left ventricular diastolic function have been demonstrated to become more prominent as the COPD stage increases. No significant association was found in the present study between the stage of COPD and the E/A ratio.

Cor pulmonale was identified in $6.25 \%$ of the patients in this study and has been shown to develop in about $25 \%$ of the patients with COPD [25]. In an autopsy series, $40 \%$ of the patients with COPD were diagnosed to have cor pulmonale [26], and about $85 \%$ of the patients with cor pulmonale had COPD [25]. Left ventricle functions were found to remain normal in COPD in some studies, while others claim that LV dysfunction may be present $[27,28]$.

Left Ventricular Systolic Dysfunction (LVSD) was present in $3.12 \%$ of the cases in the present study, while the same figure was 4-32\% among cases with COPD in previous studies [29-32]. The early detection of subclinical LVSD has been emphasized to be important in the prevention of heart failure by allowing medical treatment $[33,34]$. One cause of LVSD is RV dysfunction in COPD, while another is increased arterial rigidity $[35,36]$. In a third mechanism, the angiotensinconverting enzyme is present in very high concentrations in the lungs, and chronic hypoxemia activates the renin-angiotensin system, which, in turn, may play a role in the pathogenesis of LVSD [37]. A fourth mechanism in the development of LVSD in COPD may be the presence of systemic inflammation. Even though we did not evaluate inflammatory markers in this present study, there is powerful evidence for the presence of low-grade systemic inflammation in COPD [38-40].

In conclusion, adverse results may be inevitable when the treatment of COPD is planned targeting only the lungs. We suggest that cardiac influences should be diagnosed early in the course of the disease, and that treatment be started to decrease the rates of mortality and morbidity in patients with COPD. To 
this end, we suggest increased use of ECHO in patients with COPD in the future.

\section{Limitations of the Study}

There are some limitations in this study. Primarily, the window was not brought to a standard for the measurement of the RVOT dimension. In- and inter-observer variability is required, and RVOT dimensions are changed when different methods are used and in different sites in changing body positions. Secondly, a comparative gold standard technique was lacking for the evaluation of RV function, such as cardiac catheterization and/or magnetic resonance imaging. Thirdly, there were no female patients with COPD included in this study.

\section{References}

1. Burrows B, Fletcher CM, Heard BE. The emphysematous and bronchial types of chronic airways obstruction: a clinicopathological study of patients in London and Chicago. Lancet 1966; 1: 830-835.

2. Mathers CD, Loncar D. Projections of global mortality and burden of disease from 2002 to 2030. PLoS Med 2006; 3: e442.

3. Rabe KF, Hurd S, Anzueto A. Global initiative for chronic obstructive lung disease. Global strategy for the diagnosis, management, and prevention of chronic obstructive pulmonary disease: GOLD executive summary. Am J Respir Crit Care Med 2007; 176: 532-555

4. Yock PG, Popp RL. Noninvasive estimation of right ventricular systolic pressure by Doppler ultrasound in patients with tricuspid regurgitation. Circulation 1984; 70: 657-662.

5. Bossone E, Rubenfire M, Bach DS. Range of tricuspid regurgitation velocity at rest and during exercise in normal adult men: implications for the diagnosis of pulmonary hypertension. J Am Coll Cardiol 1999; 33: $1662-1666$.

6. Kaul S, Tei C, Hopkins JM. Assessment of right ventricular function using twodimensional echocardiography. Am Heart J 1984; 128: 301-307.

7. Lindqvist $\mathrm{P}$, Henein $\mathrm{M}$, Kazzam E. Right ventricular outflow-tract fractional shortening: an applicable measure of right ventricular systolic function. Eur J Echocardiogr 2003; 4: 29-35.

8. Lawrence $\mathrm{G}$, Guidelines for the echocardiographic assessment ofthe right heart in adults: a report from the American society of echocardiography endorsed by the European association of echocardiography, a registered branch of the European society of cardiology, and the Canadian society of echocardiography. J Am Soc Echocardiogr 2010; 23: 685-713.

9. Rappaport E. Cor pulmonale. Textbook of respiratory medicine (4th Edn.). Philadelphia W.B. Saunders 2000; 1631-1648.
10. Gao Y, Du X, Liang L. Evaluation of right ventricular function by 64-row $\mathrm{CT}$ in patients with chronic obstructive pulmonary disease and cor pulmonale. Eur J Radiol 2012; 81: 345-353.

11. Gao Y, Du X, Qin W. Assessment of the right ventricular function in patients with chronic obstructive pulmonary disease using MRI. Acta Radiol 2011; 52: 711-715.

12. Watz H, Waschki B, Boehme C. Extrapulmonary effects of chronic obstructive pulmonary disease on physical activity: a cross-sectional study. Am J Respir Crit Care Med 2008; 177: 743-751.

13. Arcasoy SM, Christie JD, Ferrari VA. Echocardiographic assessment of pulmonary hypertension in patients with advanced lung disease. Am J Respir Crit Care Med 2003; 167: 735-740.

14. Tramarin R, Torbicki A, Marchandise B. Doppler echocardiographic evaluation of pulmonary artery pressure in chronic obstructive pulmonary disease. A European multicentre study. Working Group on Noninvasive Evaluation of Pulmonary Artery Pressure. European Office of the World Health Organization, Copenhagen. Eur Heart J 1991; 12: 103-111.

15. Weitzenblum E, Chaouat A, Oswald M. Pulmonary hypertension due to chronic hypoxic lung disease. Pulmonary Circulation Chapman Hall London 1996; 157-170.

16. Barbera JA, Blanco I. Pulmonary hypertension in patients with chronic obstructive pulmonary disease: advances in pathophysiology and management. Drugs 2009; 69: 1153-1171.

17. British Thoracic Society. BTS guidelines for the management of chronic obstructive pulmonary disease. Diagnosis and management of stable COPD. Thorax 1997; 52: 7-15.

18. Rudski LG, Lai WW, Afilalo J. Guidelines for the echocardiographic assessment of the right heart in adults: a report from the American Society of Echocardiography endorsed by the European Association of Echocardiography, a registered branch of the European Society of Cardiology, and the Canadian Society of Echocardiography. J Am Soc Echocardiogr 2010; 23: 685-713.

19. Asmer I, Adawi S, Ganaeem M. Right ventricular outflow tract systolic excursion: a novel echocardiographic parameter of right ventricular function. Eur Heart J Cardiovasc Imaging 2012; 13: 871-877.

20. Geyik B, Tarakci N, Ozeke O. Right ventricular outflow tract function in chronic obstructive pulmonary disease. Herz 2015; 40: 624-628.

21. Onbasili OA, Polatli M, Tekten T, ve ark. Kronik Obstruktif Akciger Hastaligi Olan Olgularda Sag Ventrikül Fonksiyonlarinin Miyokard Performans Indeksi Yöntemi ile Degerlendirilmesi: Saglikli Bireylerle Karsilastirmali Çalisma. Turkiye Klinikleri J Cardiol 2004; 17: 33-41. 
22. Ozer N, Tokgozoglu L, Coplu L. Echocardiographic evaluation of left and right ventricular diastolic function in patients with chronic obstructive pulmonary disease. J Am Soc Echocardiogr 2001; 14: 557-561.

23. Karabulut A, Iltumur K, Durak D, Nizamettin Toprak. Sag Ventrikul Diastolik Fonksiyonlarinin Kronik Obstruktif Akciger Hastaliginin Evrelerine Gore Degerlendirilmesi. Dicle Tip Dergisi 2005; 32: 145-148.

24. Yemenici H, Yilmaz A, Kilci H.Kronik Obstrüktif Akciger Hastaliginda Sag Ventrikül Diyastolik Fonksiyonun Degerlendirilmesi. Türk Toraks Derg 2012; 13: $152-157$

25. Springhouse. Respiratory disorders. Professional Guide to Diseases (9th Edn.). Philadelphia Lippincott William and Wilkins 2008; 120.

26. Rigolin VH, Robiolio PA, Wilson JS, Harrison JK, Bashore TM. The forgotten chamber: The importance of the right ventricle. Cathet Cardiovasc Diagn 1995; 35: $18-28$.

27. Murphy ML, Adamson J, Hutcheson F. Left ventricular hypertrophy in patients with chronic bronchitis and emphysema. Ann Intern Med 1974; 81: 307-313.

28. Fluck DC, Chandrasekar RG, Gardner FV. Left ventricular hypertrophy in chronic bronchitis. Br Heart J 1966; 28: 92-97.

29. Render, ML, Weinstein, AS, Blaustein, AS Left ventricular dysfunction in deteriorating patients with chronic obstructive pulmonary disease. Chest 1995; 107: 162-168.

30. Vizza CD, Lynch JP, Ochoa LL, Richardson G, Trulock EP. Right and left ventricular dysfunction in patients with severe pulmonary disease. Chest 1998; 113; 576-583.

31. Jardin F, Gueret P, Prost JF, Farcot JC, Ozier Y, Bourdarias JP. Two-dimensional echocardiographic assessment of left ventricular function in chronic obstructive pulmonary disease. Am Rev Respir Dis 1984; 129: $135-142$.
32. Louridas G, Patakas D, Stavropoulos C. Left ventricular function in patients with chronic obstructive pulmonary disease. Cardiology 1981; 67: 73-80.

33. Nakai H, Takeuchi M, Nishikage T. Subclinical left ventricular dysfunction in asymptomatic diabetic patients assessed by twodimensional speckle tracking echocardiography: correlation with diabetic duration. Eur J Echocardiogr 2009; 10: 926-932.

34. Henein MY, Gibson DG. Long axis function in disease. Heart 1999; 81: 229-231.

35. Sabit R, Bolton CE, Fraser AG. Sub-clinical left and right ventricular dysfunction in patients with COPD. Respir Med 2010; 104: 1171-1178.

36. Aykan AC, Gokdeniz T, Boyaci F. Assessment of arterial stiff ness in chronic obstructive pulmonary disease by a novel method: Cardio-ankle vascular index. Herz 2013.

37. Bhatt SP, Dransfield MT. Chronic obstructive pulmonary disease and cardiovascular disease. Transl Res 2013; 162: 237-251.

38. Sin DD, Man SF. Chronic obstructive pulmonary disease: a novel risk factor for cardiovascular disease. Can J Physiol Pharmacol 2005; 83: 8-13.

39. Cavailles A, Brinchault-Rabin G, Dixmier A. Comorbidities of COPD. Eur Respir Rev 2013; 22: 454-475.

40. Ozben B, Eryuksel E, Tanrikulu AM. Acute exacerbation impairs endothelial function in patients with chronic obstructive pulmonary disease. Turk Kardiyol Dern Ars 2010; 38: 1-7.

\section{*Correspondence to}

Pinar Mutlu

Clinic of Chest Diseases

Can State Hospital

Turkey 